\title{
ARTICLE
}

\section{Self-Assembly of Block Copolymers during Hollow Fiber Spinning: An In Situ Small-Angle X-Ray Scattering Study}

Kirti Sankhala ${ }^{1}$, D. C. Florian Wieland ${ }^{2}$, Joachim Koll ${ }^{1}$, Maryam Radjabian ${ }^{1}$, Clarissa Abetz ${ }^{1}$, Volker Abetz ${ }^{1,3 *}$

1 Helmholtz-Zentrum Geesthacht, Institute of Polymer Research, Max-Planck-Strasse 1, 21502 Geesthacht, Germany

2 Helmholtz-Zentrum Geesthacht, Institute of Materials Research, Max-Planck-Strasse 1, 21502 Geesthacht, Germany

${ }^{3}$ University of Hamburg, Institute of Physical Chemistry, Martin-Luther-King-Platz 6, 20146 Hamburg, Germany

*E-mail: volker.abetz@hzg.de 


\section{ABSTRACT}

We investigated the self-assembly of block copolymers during hollow fiber membrane (HFM) fabrication by conducting in situ small angle X-ray scattering (SAXS) and ex situ scanning electron microscopy (SEM) studies. SAXS enables us to follow the structural rearrangements after extrusion at different distances from the spinning nozzle. The kinetics of the spinning process is examined as a function of the composition of block copolymer solutions and the spinning parameters. We studied the influence of the extrusion rate on the block copolymer microdomains and their self-assembly in weakly segregated and ordered solutions. The addition of magnesium acetate $\left(\mathrm{MgAc}_{2}\right)$ leads to ordering of micelles in the block copolymer solution already at lower polymer concentrations and shows an increased number of micelles with larger domain spacing as compared to the pristine solution. The SAXS data show the effect of shear within the spinneret on the self-assembly of block copolymers and the kinetics of phase separation after extrusion. It is observed that the ordering of micelles in solutions is decreased as indicated by the loss of crystallinity while high extrusion rates orient the structures perpendicular to the fiber direction. The structural features obtained from in situ SAXS experiments are correlated to the structure in the block copolymer solutions in absence of shear and the morphologies in flat sheet and HF membranes obtained by ex situ SEM. This allows a systematic and comparative study of the effects varying the microdomain ordering within different block copolymer solutions and the formed membrane structures.

\section{KEYWORDS:}

block copolymer, self-assembly, in situ SAXS, isoporous membrane, isoporous hollow fiber membrane

\section{Highlight of work:}

Study of the self-assembly of block copolymers in ordered and weakly segregated solutions after extrusion during fabrication of isoporous hollow fiber membranes.

\section{Graphical Abstract/TOC}

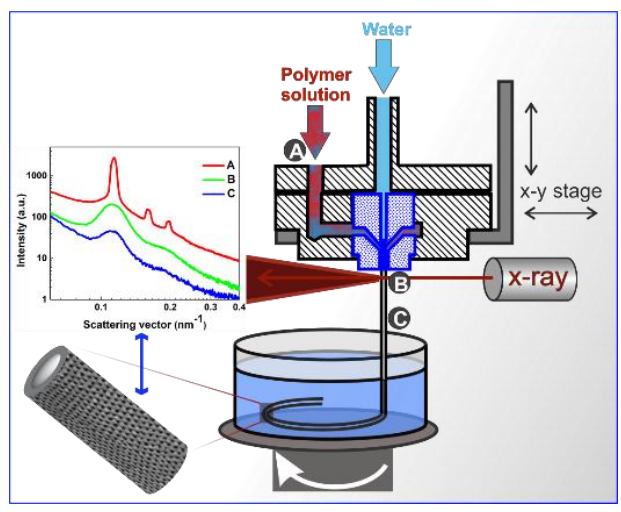




\section{Introduction}

The self-assembly of block copolymers enables the design of highly ordered nanostructures. Covalently bound incompatible block segments tend to exhibit microphase separation instead of a macroscopic phase separation providing lateral order of tailorable microdomains applicable for many potential purposes. ${ }^{1-8}$ The self-assembly of block copolymers can be easily trapped kinetically in metastable or other non-equilibrium states, which is a consequence of the low free-energy density of polymers in general and their structure formation kinetics, which is also often sufficiently slow for in situ observation. ${ }^{9}$ In particular, block copolymer membranes with self-assembled densely packed uniform pores can be an efficient structure in membrane technology to enhance permeability and separation efficiency. ${ }^{10-15}$ Such block copolymer membranes having an isoporous surface supported by an asymmetric and more open porous substructure can be fabricated in "one-step" via self-assembly of block copolymer in solution and non-solvent induced phase separation (SNIPS). ${ }^{16}$ The first integral asymmetric isoporous membranes were fabricated in flat sheet geometry. A solution of polystyrene-block-poly(4-vinylpyridine) (PS- $b$ P4VP) diblock copolymer in a solvent mixture of $\mathrm{N}, \mathrm{N}$-dimethylformamide (DMF) and tetrahydrofuran (THF) was cast on a nonwoven support and the as-cast film was immersed in the precipitation bath after providing a short evaporation time. The more volatile solvent THF is selective for PS while DMF is selective for pore forming minority block P4VP. ${ }^{16,17}$ Here, the self-assembly and, thus, the arrangement of uniform pores depends on the specific segregation strength of the chosen block segments, the solvents, and the concentration of the block copolymer. ${ }^{10 \text {, }}$ ${ }^{18}$ This can be further actuated by introducing small amount of additives in the block copolymer solutions, such as metal salts or carbohydrates or by applying external stimulating directional forces. ${ }^{2,19-22}$ In this study, magnesium acetate $\left(\mathrm{MgAc}_{2}\right)$ was used as an additive due to the known complexation of $\mathrm{Mg}$ cations with the pyridine moieties. A similar influence can be achieved by adding other metal salts like copper(II), nickel(II), cobalt(II), iron(II), cadmium(II) etc., however, the transition metal salts are not appropriate additives for the aimed applications of these membranes due to their often toxic nature. The additives allow to reduce the block copolymer concentration required for the onset of microphase separation, which is of great economical interest for cost reduction and resources preserving applications. In addition, the membranes prepared by using highly concentrated polymer solutions tend to form more compact structures and result therefore in lesser permeability. ${ }^{12}$

Recently, the capability of the SNIPS process to generate functionalized membranes was further improved yielding isoporous structures on the outer or the inner surface of a hollow fiber membrane (HFM). ${ }^{23-30}$ The HF geometry provides a high active surface area per unit volume and close packing of these self-supported membranes in filtration modules, which make them preferable to flat sheet membranes for large-scale installations. ${ }^{30-32}$ However, during the HF spinning process, additional structure controlling factors gain importance as the extrusion of a compressible viscoelastic polymer solution and the swelling of the extrudate afterwards affect the structure formation and performance of the formed membrane. In addition to the already mentioned parameters, factors like the spinneret (design and dimensions), spinning parameters (air gap and flow rates of polymer solution and bore fluid) and environmental conditions also influence the self-assembly. ${ }^{24,25}$ The HF spinning process has been investigated vastly 
for the fabrication of commonly used asymmetric HFM via non-solvent induced phase separation (NIPS). ${ }^{33-36}$ Pranzas et al. investigated the dynamic aggregation processes during HF spinning of polyetherimide (PEI) homopolymer by conducting in situ SAXS experiments. ${ }^{37}$ However, in fabrication of isoporous HFM, the shear induced free energy changes in the block copolymer solution during and after extrusion control the morphology and thus the performance of the formed membranes. ${ }^{5}{ }^{24}$ In HF spinning, the structure formation takes place in the air gap between the spinneret and the precipitation bath. The strain in the fiber due to the gravitational force limits the range of applicable extrusion rates and the air gap, which defines the evaporation time. Thus, a good understanding of the process is required to attain the needed control to fabricate high quality isoporous HF membranes. Open questions exists about the key parameters which direct the self-assembly of block copolymers in this very short time. After extrusion, a subtle balance exists between the block copolymers trying to reach their equilibrium state, which is disturbed due to the shear forces and the ongoing evaporation that induces self-assembly and precipitation. So far, fundamental studies have mainly been focused on the effects of solvents and block copolymer concentration in the solutions using dynamic light scattering (DLS) and synchrotron SAXS, and on the flat sheet membrane fabrication by cryo-scanning electron microscopy (SEM) and cryo-transmission electron microscopy (TEM) ${ }^{18,38-44}$ Although SAXS has been an important tool to understand various mechanisms already for a long time, e.g. by providing insights in the mechanism of phase transitions and structure development of soft matter, ${ }^{45-51}$ and in situ SAXS and grazing incidence small angle X-ray scattering (GISAXS) experiments were conducted to investigate the kinetics of structure formation during isoporous flat sheet membrane fabrication for the commonly used block copolymer solutions, ${ }^{52-55}$ the structure formation in block copolymer HFM has not been probed by in situ characterization techniques. Therefore, it is of great interest to explore the behavior of different polymer solutions at different spinning parameters after extrusion by conducting in situ SAXS experiments, enabling us to develop new pathways to tailor the structure formation in HFM.

In this study, we aim to understand the key factors driving the self-organization of PS- $b$-P4VP diblock copolymer, with and without the additive $\mathrm{MgAc}_{2}$, at different evaporation times for HF spinning. The structure formation in HF is more sensitive towards changes in the solution compositions such as the presence of additives with reduced polymer concentration as compared to flat sheet membranes. So, the weakly segregated solutions as well as the ordered solutions are investigated to check the influence of extrusion on the micellar lattices of microphase separated solutions and on the structure formation afterwards. Instead of the ordered solution with high polymer concentration, we chose the ordered solution with additive $\mathrm{MgAc}_{2}$ at comparatively lower polymer concentrations while the solvent compositions were kept constant to reduce the number of influencing parameters. For these experiments, we installed a lab scale HF spinning set-up into the beamline P03 at DESY, ${ }^{56}$ which allowed us to change the spinning parameters while simultaneously measuring the structural features by SAXS. The selected polymer solutions and the spinning parameters offer a systematic and comparative study. We identify the influence of the solution characteristics and processing parameters on the distinct microscopic mechanisms and correlate them with 
the membrane morphology, where in a certain range of spinning parameters the alignment of microdomains dominates over self-assembly of block copolymers into hexagonally packed isopores on the outer surface of HFM.

\section{Experimental section}

\subsection{SAXS of polymer solutions and bulk films}

The polymer solutions were prepared by stirring a specific concentration of PS-b-P4VP diblock copolymer, with and without additive, in a mixture of DMF/THF in equal weight ratio (wt/wt); all concentrations are given in wt\%, a detailed explanation is given in the ESI. For investigation of the polymer structure in the spinning solutions, the solutions were filled into quartz capillaries with a wall thickness of $10 \mu \mathrm{m}$ and a diameter of $2 \mathrm{~mm}$ and sealed by epoxy glue to prevent evaporation.

For the investigation of the bulk morphologies of the PS-b-P4VP diblock copolymers, films were prepared as reported in ESI. The films were characterized by SAXS and TEM, see Fig. S1 in ESI. SAXS experiments on the equilibrated films were performed on a Bruker Nanostar, Karlsruhe, Germany. The lab source is equipped with a copper anode providing an X-ray beam with an energy of $8 \mathrm{keV}$. The set-up utilizes a VANTEC-2000 detector with a pixel size of 68 $\mu \mathrm{m}$. The sample to detector distance was $1.5 \mathrm{~m}$ providing a $q$-range from 0.06 to $2.2 \mathrm{~nm}^{-1}$.

\subsection{In situ synchrotron SAXS}

The SAXS experiments were performed at the microfocus end station of the beamline P03, PETRA III, Deutsches Elektronen-Synchrotron (DESY), in Hamburg, Germany. ${ }^{56}$ An X-ray beam having an energy of $12.981 \mathrm{keV}$ was used to have a good transmission through the block copolymer solution in the shell around the bore fluid. The beam was

focused to $28 \times 14 \mu \mathrm{m}^{2}$ (horizontal $\times$ vertical) by using an assembly of parabolic beryllium compound refractive lenses. The exposure time was $0.2 \mathrm{~s}$ with a total number of 20 frames for each measurement resulting in a total acquisition time of $4 \mathrm{~s}$. Background measurements were carried out in between by moving the HF out of the beam. We used a sample-to-detector distance of $8.91 \mathrm{~m}$, which allowed a q-range from 0.04 to $1.1 \mathrm{~nm}^{-1}$ to capture all occurring structural changes in the range of ca. $5.7-157 \mathrm{~nm}$. We used the Pilatus $1 \mathrm{M}$ fast-readout detector.

For the data integration, masking and normalization the software package DAWN was used. ${ }^{57}$ The two-dimensional images were averaged azimuthally to obtain a trace of intensity vs. the scattering wave vector $q(q=4 \pi \sin (2 \vartheta / 2) / \lambda$, where $2 \vartheta$ is the scattering angle and $\lambda$ is the wavelength of the $X$-rays). The characteristic length or domain spacing $(d)$ is determined from the primary peak corresponding to the scattering vector $q^{*}$, as $d=2 \pi / q^{*}$. In a further step, the patterns were averaged radially in a certain $q$-regime, which was chosen to include the occurring structure factor. The resulting curves showing the intensity vs. the azimuthal angle allow investigating whether orientation effects are occurring or not. In the case of no orientation, a constant intensity is observed whereas for orientation effects two maxima within a distance of $180^{\circ}$ can be seen. For background subtractions, frames showing only air scattering were subtracted from the averaged data. The fitting of the correlation peaks and background subtraction were done 
using MATLAB. All the data for a distinct horizontal scan were compared. No significant variation along the crosssection of the fiber could be seen. Thus, the data at one horizontal height were averaged.

For the experiments, a standard spinning set-up was used as schematized in Fig. 3. The set-up consists of one double orifice spinneret for extrusion of polymer solution and bore fluid (water), syringes, two high-precision pumps and precipitation baths as described in our previous work for outside-in isoporous HFM fabrication. ${ }^{24}$ The used double orifice spinnerets have outer diameters of 0.32 and $1.3 \mathrm{~mm}$ for the bore fluid and polymer solution, respectively. The wall thickness separating the two orifices is $0.1 \mathrm{~mm}$. Glass syringes with Luer-lock tips were used for the experiment and were connected to spinneret via transparent polyethylene tubes. In order to get rid of air bubbles, the syringes were filled one day before the beam time and well sealed afterwards to avoid solvent evaporation. The micro-precision pumps were mounted outside the experimental hutch for easy control of the flow rates of polymer solution and bore fluid. The precision pumps and the glass syringes were connected by tubes filled with water.

The spinning system (spinneret, holder and syringes) was fixed to a remote controlled micro-precision stage to move the set-up in the plane perpendicular to the X-ray beam in order to change the distance with respect to the beam passing through the extruded fiber. A precipitation bath on a rotating motor was fixed ca. $50 \mathrm{~mm}$ below the beam on the available granite bridge. The vertical distance, between the positions of spinneret holder on the x-y stage from the beam, corresponds to a certain air gap distance $\left(L_{a}\right)$ providing a certain evaporation time for as-spun fiber. While, the horizontal moving was used to scan across the fiber with a step size of 30 to $100 \mu \mathrm{m}$.

The fibers were thoroughly scanned at different $L_{a}$ from the nozzle for various block copolymer solutions and spinning parameters, polymer flow rate $\left(Q_{p}\right)$ and bore fluid (water) flow rate $\left(Q_{w}\right)$. Simultaneously, the spun fibers were collected in a rotating precipitation bath which was located ca. $50 \mathrm{~mm}$ below the beam providing a total air gap, $L=L_{a}+50 \mathrm{~mm}$, where $L_{a}$ was varied from 1 to $80 \mathrm{~mm}$; so, there was always an additional effect of gravity and strain in the fiber during SAXS measurements. However, in order to correlate the SAXS curves and HFM morphology influenced by spinning parameters and solution characteristics, the HF spinnings were repeated in the lab. In the repeated HF spinning for morphological investigations by SEM, the structures in as-spun fibers were quenched at particular $L_{a}$ (so, $L=L_{a}$ ). We note that scanning along the fiber by keeping a constant air gap was not possible. Constructing a set-up where the air gap could be kept constant while scanning along the fiber would have been too heavy for the available micro-precision motor stages. Therefore, the water bath was fixed at the bottom of the beamline and only the spinning system was motorized.

The data were integrated azimuthally and radially in order to get the scattered intensity as function of $q$ and as function of the azimuthal angle to check for orientation effects.

\subsection{Membrane fabrication and morphological characterization}

To fabricate the flat sheet membranes, the polymer solution was cast on a glass plate using a doctor blade with gap height of $200 \mu \mathrm{m}$ and immersed in the precipitation bath after providing an evaporation time of 2 and $5 \mathrm{~s}$, 
respectively. During flat sheet membrane fabrication, the relative humidity in the lab was ca. $20 \%$ and the ambient temperature was ca. $20^{\circ} \mathrm{C}$.

For morphological investigations in $\mathrm{HF}$, we repeated the experiments with spinning conditions (spinneret, spinneret holder), spinning parameters ( $L_{a}, Q_{p}$ and $Q_{w}$ ) and the polymer solutions (with recycled block copolymers) similar to the in situ SAXS experiments to achieve the same morphologies. The environmental conditions during HFM fabrications were ca. $30-40 \%$ for relative humidity and ca. $21-26^{\circ} \mathrm{C}$ for ambient temperature.

The morphology of flat sheet membranes and HFM were evaluated by a SEM LEO 1550VP (Carl ZEISS, Oberkochen, Germany), at an accelerating voltage of 2-5 kV. To investigate the surface morphology of the membranes, individual pieces were cut and fixed on the sample holders. For the study of the cross-section morphology, the samples were prepared under cryogenic condition (fracturing in liquid nitrogen). All the samples were sputtered with ca. $2 \mathrm{~nm}$ thin conductive layer of Pt.

\section{Results and discussion}

\subsection{Influence of block copolymer solution on membrane morphology}

Table 1. Details of PS- $b$-P4VP block copolymers and their bulk characterization. For PS- $b$-P4VP $a^{b}, a$ denotes the amount of P4VP block in wt\% and $b$ denotes $M_{n}$, where $M_{n}$ is number averaged molecular weight in $\mathrm{kg} \mathrm{mol}^{-1} . \oplus$ is dispersity of the respective block copolymer. $q_{\text {bulk }}{ }^{*}$ is the primary peak corresponding to the scattering vector and $d_{b u l k}=2 \pi / q_{\text {bulk }}{ }^{*}$ is the characteristic length or domain spacing of the bulk block copolymer film. All $q^{*}$ and $d$ have an error bar of $\pm 0.002 \mathrm{~nm}^{-1}$ and $\pm 0.6 \mathrm{~nm}$, respectively.

\begin{tabular}{|l|l|l|l|l|l|l|}
\hline Block copolymer & $\begin{array}{l}M_{n} \\
\left(\mathrm{~kg} \mathrm{~mol}^{-1}\right)\end{array}$ & $\begin{array}{l}\mathrm{PS} \\
(\mathrm{wt} \%)\end{array}$ & $\begin{array}{l}\mathrm{P} 4 \mathrm{VP} \\
(\mathrm{wt} \%)\end{array}$ & $\oplus$ & $\begin{array}{c}q_{\text {bulk }}{ }^{*} \\
\left(\mathrm{~nm}^{-1}\right)\end{array}$ & $\begin{array}{l}d_{\text {bulk }} \\
(\mathrm{nm})\end{array}$ \\
\hline $\mathrm{PS}-b-\mathrm{P}_{\mathrm{VVP}}{ }_{18}^{150}$ & 150 & 82 & 18 & 1.04 & 0.172 & 36.5 \\
\hline $\mathrm{PS}-b-\mathrm{P}_{\mathrm{V} \mathrm{P}_{19}}{ }^{170}$ & 170 & 81 & 19 & 1.07 & 0.152 & 41.2 \\
\hline
\end{tabular}
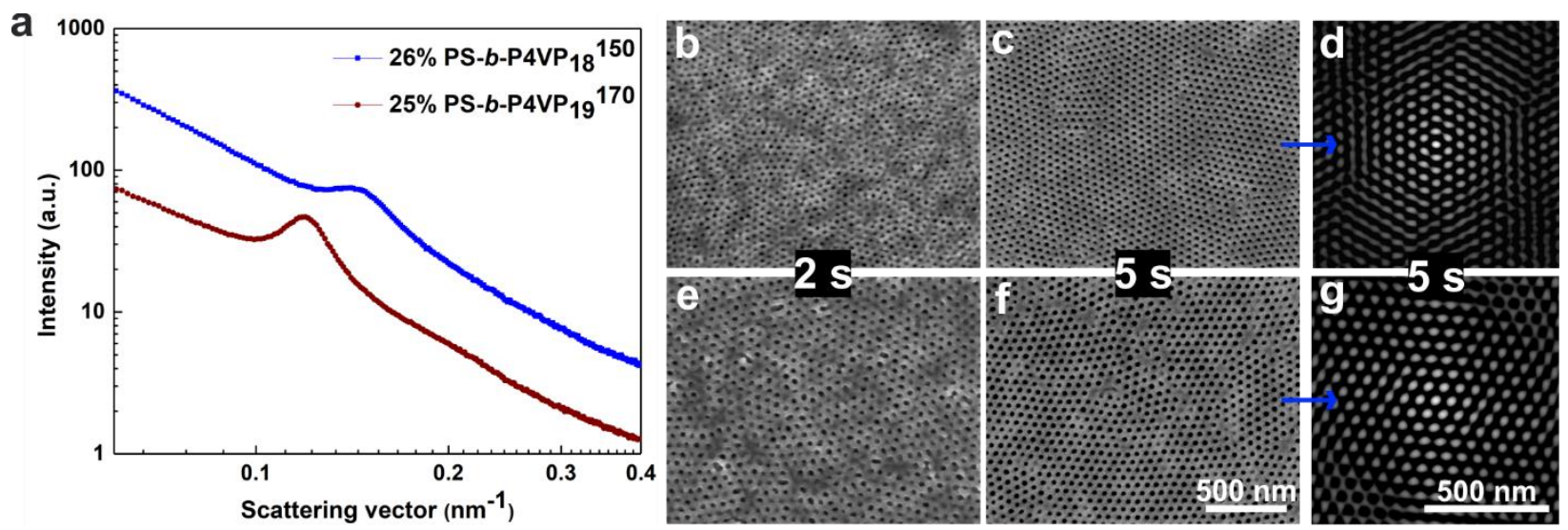

Fig. 1. SAXS of casting solutions and SEM micrographs of fabricated membranes. (a) The SAXS curves of solutions, which are adjusted vertically for clarity. (b,c,e,f) SEM micrographs of the top surface of blade-cast membranes from the weakly segregated solutions $26 \mathrm{wt} \% \mathrm{PS}-b-\mathrm{P}_{\mathrm{VVP}}{ }_{18}{ }^{150}(\mathrm{~b}, \mathrm{c})$ and $25 \mathrm{wt} \% \mathrm{PS}-b-\mathrm{P}_{\mathrm{VVP}}{ }_{19}{ }^{170}$ (e,f) in DMF/THF 50/50 (wt/wt); evaporation times were $2 \mathrm{~s}$ (b,e) 
and $5 \mathrm{~s}(\mathrm{c}, \mathrm{f}) .(\mathrm{d}, \mathrm{g})$ The micrographs show autocorrelated patterns of SEM micrographs $c$ and $f$. The micrographs $b, c, e, f$ and $d, g$ have the same scale bar.

Table 2. List of PS- $b$-P4VP block copolymer solutions. All $q^{*}$ and $d$ have an error bar of $\pm 0.001 \mathrm{~nm}^{-1}$ and $\pm 0.4 \mathrm{~nm}$, respectively.

\begin{tabular}{|c|c|c|c|}
\hline Block copolymer & Polymer solution (in DMF/THF 50/50 (wt/wt)) & $\begin{array}{c}q^{*} \\
\left(\mathrm{~nm}^{-1}\right)\end{array}$ & $\begin{array}{c}d \\
(\mathrm{~nm})\end{array}$ \\
\hline PS- $b-P_{4 V P_{18}} 150$ & $26 w t \%$ PS- $b-P 4 V_{18}{ }^{150}$ & 0.147 & 42.7 \\
\hline \multirow[t]{4}{*}{ PS- $b-\mathrm{P} 4 \mathrm{VP}_{19}{ }^{170}$} & 25 wt\% PS- $b-P 4 V_{19}{ }^{170}$ & 0.120 & 52.4 \\
\hline & 28 wt\% PS-b-P4VP 19170 & 0.117 & 53.7 \\
\hline & 23 wt\% PS-b-P4VP $19{ }^{170}$ and 1.0 wt $\% \mathrm{MgAc}_{2}$ & 0.114 & 55.1 \\
\hline & $21 \mathrm{wt} \% \mathrm{PS}-b-\mathrm{P} 4 \mathrm{VP}_{19}{ }^{170}$ and $1.5 \mathrm{wt} \% \mathrm{MgAc}_{2}$ & 0.114 & 55.1 \\
\hline
\end{tabular}

In order to identify appropriate solution conditions required for steady HF spinning and periodic nanostructure formation, the solution compositions, the composition and molecular weight of the block copolymers were chosen in the range of our previously reported work on HFM. ${ }^{24,25}$ The details of selected block copolymers and their bulk characterization are given in Table 1, more details about bulk characterization (SAXS curves and TEM micrographs) and the film fabrication are given in ESI (Fig. S1). The block copolymer solutions used in this work are reported in Table 2. The isoporous structure formation using these solutions was checked in flat sheet membranes prior to the SAXS experiments. The optimized concentration for the block copolymers PS- $b$-P4VP $18{ }^{150}$ and PS- $b$-P $4 \mathrm{VP}_{19}{ }^{170}$ were found to be $26 \mathrm{wt} \%$ and $25 \mathrm{wt} \%$ in the solvents DMF/THF 50/50 (wt/wt), respectively (Fig. 1 and Table 2). The SAXS patterns of the block copolymer solutions show a single broad peak indicating a weakly segregated solution where the copolymers are associated in micellar aggregates. The details of SEM micrographs in Table S2 show that the increase in segregation with increase in concentration, due to the evaporation of solvent(s), leads to the formation of more open pores with reduced average center-to-center distance between pores $\left(d_{c-c}\right)$. The SEM micrographs in Figs. 1c,f have the hexagonal arrangement of pores, which is shown by autocorrelated patterns in Figs. 1d,g.

With an increase of the PS- $b$-P $4 \mathrm{VP}_{19}{ }^{170}$ block copolymer concentration from $25 \mathrm{wt} \%$ to $28 \mathrm{wt} \%$, the macromolecules self-assemble, which lead to the formation of a crystalline phase by spontaneous packing of micelles into an ordered lattice (Fig. 2a). Due to the increased segregation, the domain spacing increases from $52.3 \pm 0.4 \mathrm{~nm}$ to $53.7 \pm 0.4 \mathrm{~nm}$. As shown in Fig. 2a and Table S1, the primary peak with two clear higher-order peaks correspond to the peak positions $\left(q / q^{*}\right)^{2}=1,2$ and 3, which indicate a well-developed body centered cubic (bcc) structure. We note that this data is normally not sufficient to rule out simple cubic packing, but based on experimental and theoretical results, bcc is almost undoubtedly the actual symmetry. ${ }^{18} \mathrm{~A}$ similar reversible disorder-order transition in solution was observed previously, however, indicating a 2D hexagonally packed cylindrical (hcp) structure. ${ }^{38}$ This difference of structure in solutions might be a result of different block copolymer and solution compositions.

As mentioned before, the ability of nitrogen atoms of the vinyl pyridine units to coordinate with the $\mathrm{Mg}(\mathrm{II})$ ion of $\mathrm{MgAc}_{2}$ facilitates the structure formation of the PS- $b$-P4VP block copolymer. ${ }^{20}$ Interestingly, the SAXS curves in Fig. 2a show that with addition of $\mathrm{MgAc}_{2}$ the ordered micellar structure could be observed at comparatively lower block copolymer concentrations due to the selectivity of $\mathrm{MgAc}_{2}$ to one particular block (P4VP), which increases segmental 
incompatibility. As far as we are aware, such an ordered phase is reported for the first time for a diblock copolymer solution with $\mathrm{MgAc}_{2}$ as additive. As shown in Fig. 2a and Table $\mathrm{S} 1$, the addition of $1.0 \mathrm{wt} \% \mathrm{MgAc}_{2}$ in conjunction with a decreased polymer concentration of $23 \mathrm{wt} \%$ of PS- $b$-P $4 \mathrm{VP}_{19}{ }^{170}$ leads to the formation of a lyotropic liquid crystalline phase in form of a bcc structure with a domain spacing of $55.1 \pm 0.4 \mathrm{~nm}$. A further increase in the concentration of $\mathrm{MgAc}_{2}$ to $1.5 \mathrm{wt} \%$ and a decrease in the block copolymer amount to $21 \mathrm{wt} \%$ shows an increased peak height due to more prominent micelles, with equal domain spacing $55.1 \pm 0.4 \mathrm{~nm}$. It also seems that under these conditions two different bcc phases are present as the scattering curves indicate a peak splitting for the higher order peaks. Moreover, the ordered solution with $1.5 \mathrm{wt} \% \mathrm{MgAc}$ of comparatively very low block copolymer concentration of 21 $w t \%$ shows a larger domain spacing and peak heights as compared to the solution with $28 \mathrm{wt} \%$ block copolymer concentration. This small increase in characteristic length points toward an increase in the volume of pore forming P4VP microdomains because the selective incorporation of $\mathrm{MgAc}_{2}$ leads to a stronger segregation as compared to highly concentrated neat solutions. The increase in segregation minimizes unfavorable contacts between PS and P4VP and therefore minimizes the overall enthalpic interaction. The Flory-Huggins-Staverman interaction parameter $(\chi)$ is effectively increased and the size of the micelles increases. Moreover, the increased $\chi$ moves the orderdisorder transition farther that will be discussed in section 2.3 .
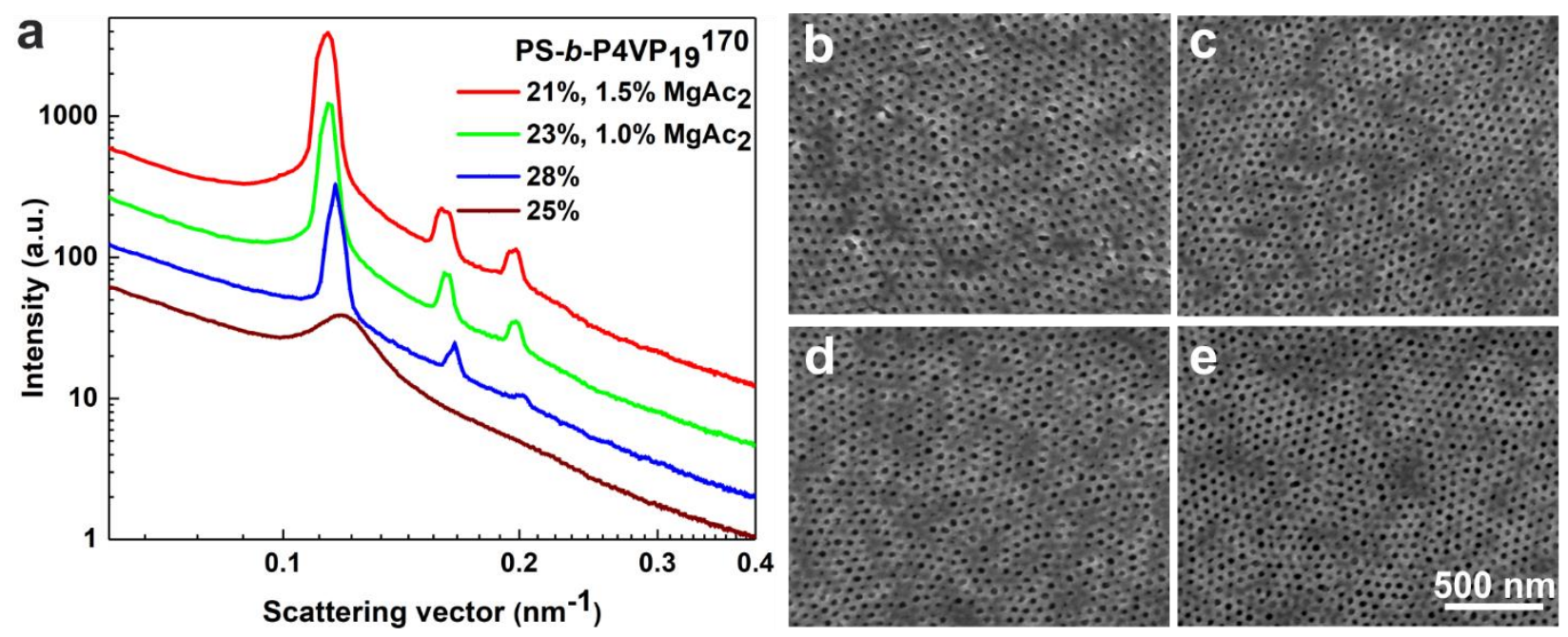

Fig. 2. SAXS of casting solutions and membrane fabrication. (a) The SAXS patterns; the SAXS curves of each solution is adjusted vertically for clarity. (b-e) SEM micrographs of the top surface of blade-cast membranes from the PS- $b$-P4VP $19^{170}$ solutions having different polymer concentration (and additive) in DMF/THF 50/50 (wt/wt) and evaporation time 2 s: 25 wt\% (b); 28 wt\% (c); 23 $w t \%, 1.0$ wt\% $\mathrm{MgAc}_{2}$ (d); 21 wt\%, $1.5 \mathrm{wt} \% \mathrm{MgAc}_{2}$ (e). The SEM micrographs b-e have the same scale bar.

The SEM micrographs in Figs. 2b-e show the possibility to achieve hexagonally packed pores on top of flat sheet membranes for very short evaporation times using both disordered micellar (25wt\%) and ordered (28 wt\%, $23 \mathrm{wt} \%$ and $1.0 \mathrm{wt} \% \mathrm{MgAc}_{2}$, and $21 \mathrm{wt} \%$ and $1.5 \mathrm{wt} \% \mathrm{MgAc}_{2}$ ) solutions. Similar disorder-order and order-order transitions 
have been reported from disordered or bcc in solution to hcp in membranes. ${ }^{18,38,55,58,59}$ The disorder-order transition is defined as the transition where long-range order appears and distinct micelles can be discerned from a disordered casting solution experimentally, while the order-order transition occurs from a bcc lattice in the casting solution to the hexagonal close packed open pores in the membrane. To compare the structure formation occurring at short solvent evaporation times, which would be relatively similar to the HF spinning, the structure of the solutioncast films were quenched by immersing them into the precipitation bath after $2 \mathrm{~s}$. The growth of microdomains occurs very quickly, so the morphology representing the hand-cast membranes for evaporation time $2 \mathrm{~s}$ may differ slightly; the approx. values of average pore diameter $\left(D_{p}\right)$ and $d_{c-c}$ of these membranes are given in Table S2.

\subsection{Influence of spinning parameters on structure formation in HFM}

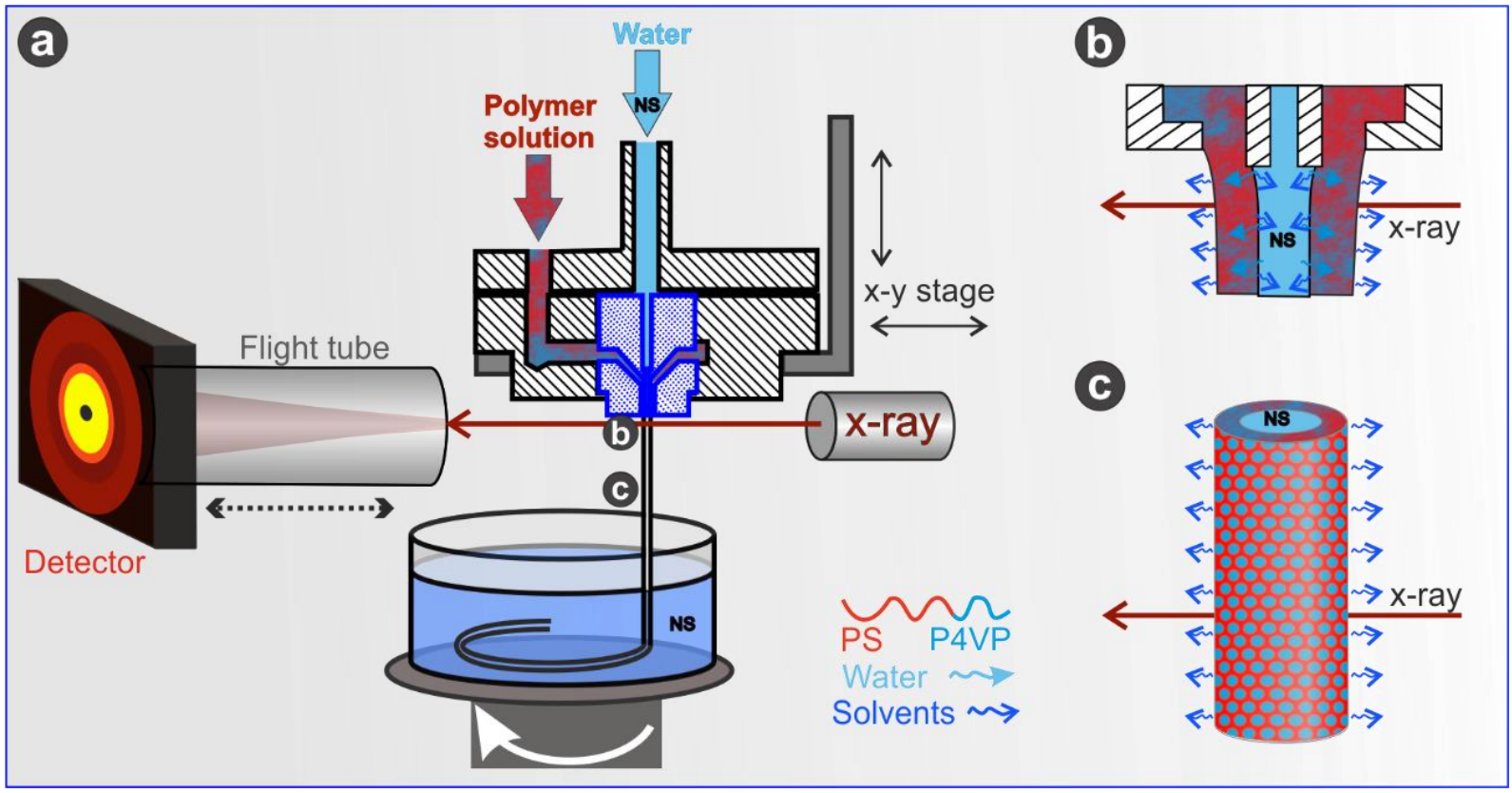

Fig. 3. Experimental overview. (a) Set-up of spinning apparatus installed at the beamline P03 of PETRA III at DESY for in situ SAXS investigations. (b) As the polymer solution is extruded through the spinneret having non-solvent (NS) in the lumen, the polymer chains relax and the volatile solvents start to evaporate from the outer surface. The as-spun fiber could be investigated closest at $1 \mathrm{~mm}$ from the nozzle of the spinneret. (c) $L_{a}$ was varied up to $80 \mathrm{~mm}$, the microphase separated structures develop on the outer surface of HF. The spun HF are collected in the precipitation bath.

For the interpretation of the experimental data, it is important to remember the main properties controlling the structure formation. As schematized in Fig. 3, in fabrication of isoporous HFM, the main implication is the occurrence of evaporation induced self-assembly of block copolymers, which initiates just after extrusion. For a certain $L_{a}$, the selection of $Q_{p}$ determines the evaporation time. A relatively similar evaporation time can be provided at a higher $Q_{p}$ along with a higher $L_{a}$. However, the kinetics of the self-assembly for both cases will significantly differ as the shear thinning of the polymer solution in the spinneret at the higher $Q_{p}$ as well as the increase in the gravitational 
force acting on the nascent fiber in the air gap. ${ }^{24}$ Thus, desired morphologies are achieved by controlling the distinct balance between the relaxation of the polymer chains due to the shear forces driving them out of equilibrium and the macromolecular rearrangement due to the evaporation of the more volatile solvent (THF), which fixes the PS matrix while the P4VP microdomains are highly swollen in DMF (Figs. 3b and 3c). This process of self-organization stops as soon as the HFM is immersed in the precipitation bath. Therefore, the study on the self-assembly of macromolecules in $\mathrm{HF}$ is focused on to the changes happening in the gap between the spinneret and the precipitation bath.

\subsubsection{Influence of polymer flow rate.}
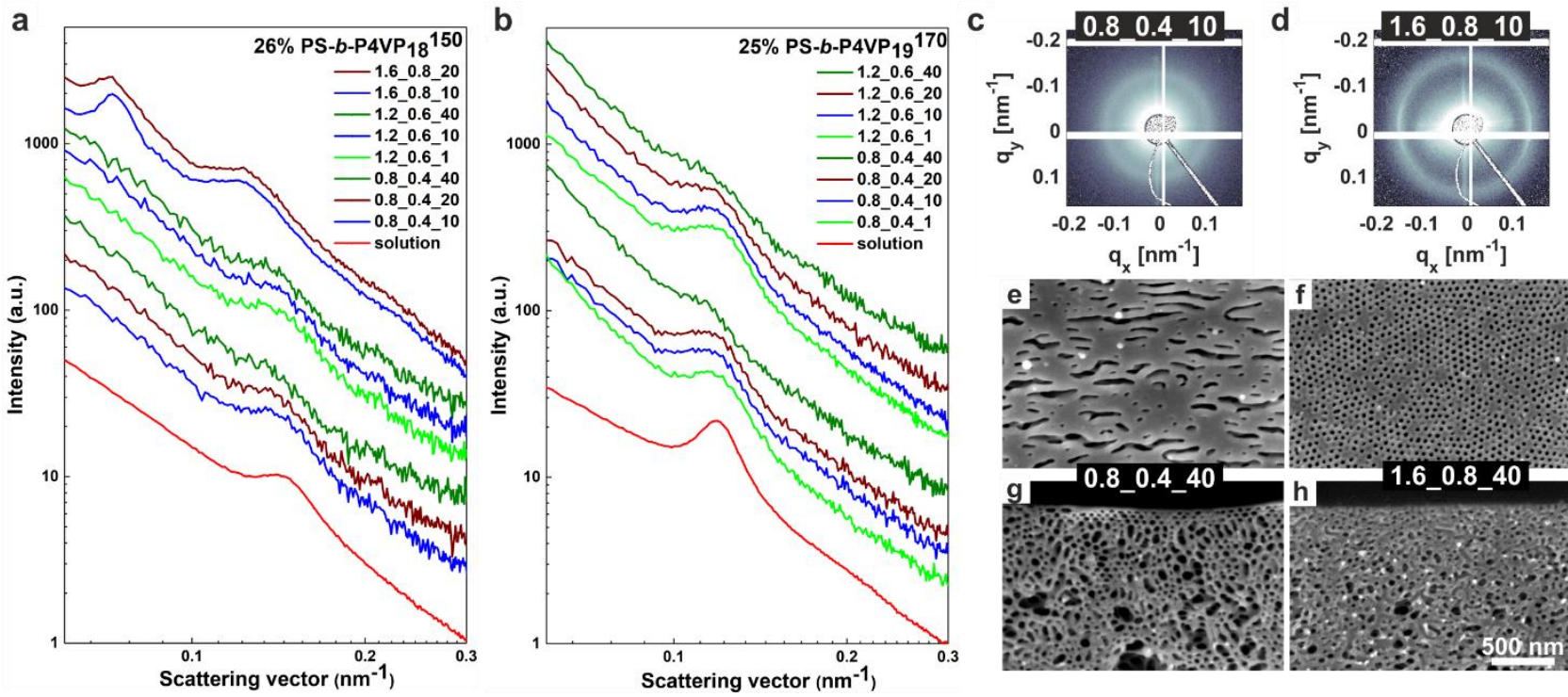

Fig. 4. Influence of $\boldsymbol{Q}_{p}$ : (a,b) SAXS curves, (c,d) SAXS patterns, and (e-h) SEM micrographs of as-spun HF using block copolymer solution 26 wt\% PS-b-P4VP $18{ }^{150}$ (a,c,d) and 25 wt\% PS-b-P4VP $19^{170}$ (b,e-h) in DMF/THF 50/50 (wt/wt) at different spinning parameters. The spinning parameters polymer and bore fluid flow rate $(\mathrm{mL} / \mathrm{min})$ are mentioned as $Q_{p}$ and $Q_{w}$, respectively, and the air gap as $L_{a}(\mathrm{~mm})$; the set of parameters in figures can be followed as $Q_{p_{-}} Q_{w_{-}} L_{a}$. The SAXS data are plotted in log-log scale and $\mathrm{Y}$-offset is adjusted for better visibility. (c,d) The images show the ring origination from the domain correlation. The fiber runs in the vertical direction and is slightly tilted due to the movement of the precipitation bath. (e-h) The SEM micrographs show the influence of spinning parameters $\left(Q_{p_{-}} Q_{w_{-}} L_{a}\right)$ on the morphology of the outer surface $(\mathrm{e}, \mathrm{f})$, cross-sections near the outer surface (g,h). The SEM micrographs e-h have same scale bar.

Table 3. Details of SAXS curves of as-spun fibers using block copolymer solutions having 26 wt $\%$ PS- $b$-P4VP 18 and 25 wt $\%$ PS$b$-P4VP 19170 in DMF/THF 50/50 (wt/wt) for different spinning parameters $\left(Q_{p_{-}} Q_{w_{-}} L_{a}\right)$. All $q^{*}$ and $d$ have an error bar of \pm 0.005 $\mathrm{nm}^{-1}$ and $\pm 1.1 \mathrm{~nm}$, respectively.

\begin{tabular}{|c|c|c|c|c|c|c|c|c|c|c|}
\hline \multirow{2}{*}{$\begin{array}{c}L_{a} \\
(\mathrm{~mm})\end{array}$} & \multicolumn{2}{|c|}{26 wt\% (0.8_0.4_La) } & \multicolumn{2}{|c|}{26 wt\% (1.2_0.6_La) } & \multicolumn{2}{|c|}{26 wt\% (1.6_0.8_La) } & \multicolumn{2}{|c|}{25 wt\% (0.8_0.4_ $\left.L_{a}\right)$} & \multicolumn{2}{|c|}{25 wt\% (1.2_0.6_La) } \\
\hline & $q^{*}\left(\mathrm{~nm}^{-1}\right)$ & $d(\mathrm{~nm})$ & $q^{*}\left(\mathrm{~nm}^{-1}\right)$ & $d(\mathrm{~nm})$ & $q^{*}\left(\mathrm{~nm}^{-1}\right)$ & $d(\mathrm{~nm})$ & $q^{*}\left(\mathrm{~nm}^{-1}\right)$ & $d(\mathrm{~nm})$ & $q^{*}\left(\mathrm{~nm}^{-1}\right)$ & $d(\mathrm{~nm})$ \\
\hline
\end{tabular}




\begin{tabular}{|c|c|c|c|c|c|c|c|c|c|c|}
\hline Solution & 0.147 & 42.7 & \multicolumn{4}{|c|}{ - } & 0.120 & 52.4 & \multicolumn{2}{|c|}{ - } \\
\hline 1 & - & - & 0.144 & 43.6 & - & - & 0.120 & 52.4 & 0.120 & 52.4 \\
\hline 10 & 0.141 & 44.6 & 0.139 & 45.2 & 0.131 & 47.9 & 0.117 & 53.7 & 0.119 & 52.8 \\
\hline 20 & 0.138 & 45.5 & & & 0.133 & 47.2 & 0.116 & 54.2 & 0.116 & 54.2 \\
\hline 40 & 0.135 & 46.5 & 0.136 & 46.2 & - & - & 0.113 & 55.6 & 0.113 & 55.6 \\
\hline
\end{tabular}

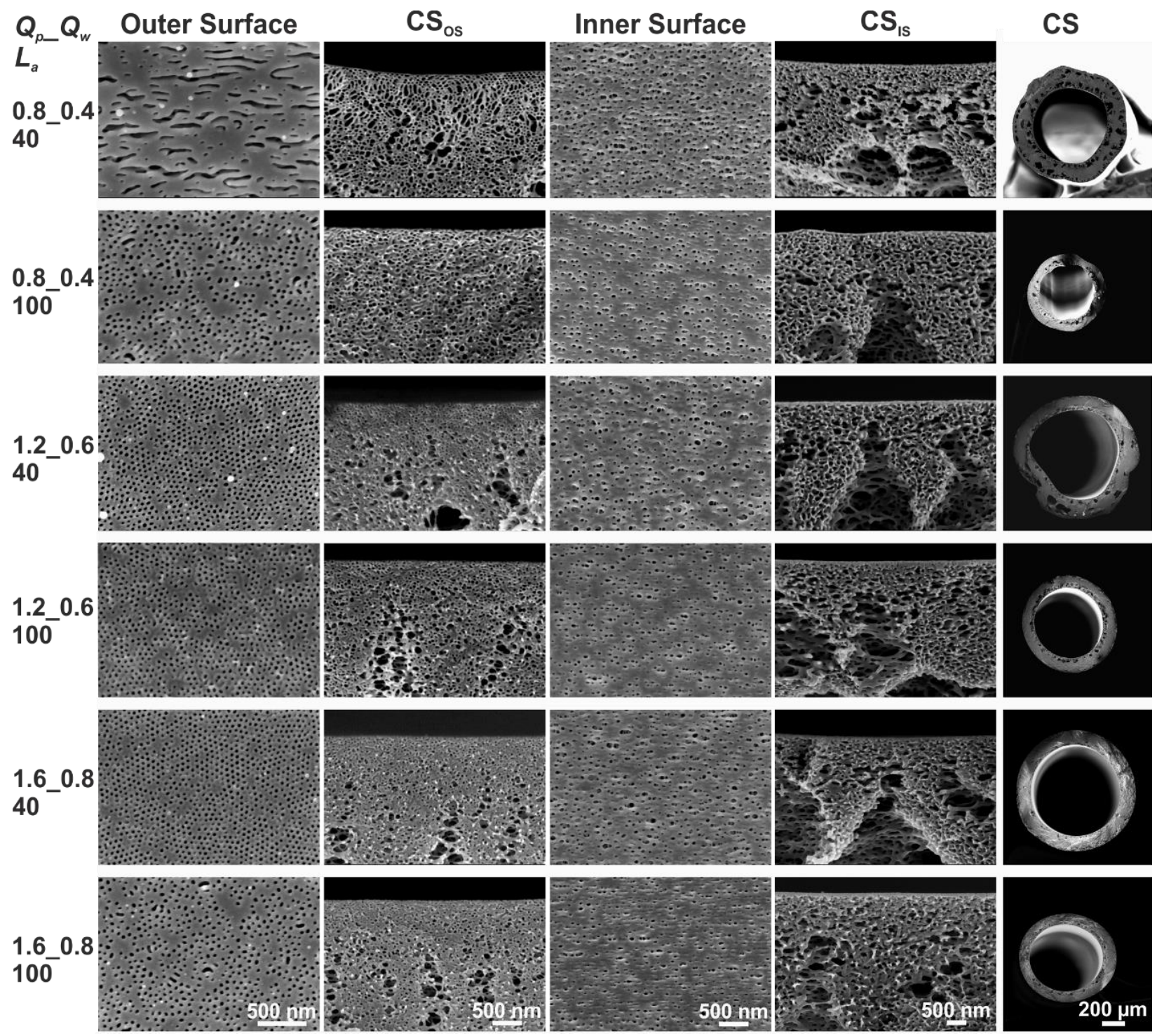

Fig. 5. The SEM micrographs show the influence of spinning parameters $\left(Q_{p_{-}} Q_{w_{-}} L_{a}\right)$ on the morphology of the outer surface, cross-sections near the outer surface $\left(\mathrm{CS}_{\mathrm{os}}\right)$, the inner surface, cross-sections near the inner surface $\left(\mathrm{CS}_{\text {is }}\right)$ and the full cross-section (CS) of HFM. The HFM were spun using block copolymer solution of $25 \mathrm{wt} \% \mathrm{PS}-b-\mathrm{P} 4 \mathrm{VP} 19^{170}$ in DMF/THF 50/50 (wt/wt) for $Q_{p} 0.8$, 1.2 and $1.6 \mathrm{~mL} / \mathrm{min}$, at $L=L_{a}, 40$ and $100 \mathrm{~mm}$. The SEM micrographs in a column have the same scale bar. 
Initially, the spinning solution is in a thermodynamically stable equilibrium as a weakly segregated spherical block copolymer solution. The extrusion of this viscoelastic solution through a spinneret disturbs this equilibrium by inducing uniaxial deformation as a result of the shear force. This deformation depends on various factors such as polymer solution, extrusion rate, spinneret design, die gap for extrusion, roughness of spinneret walls etc. In the reported in situ experiments, all the used spinnerets were made of the same material and the dimensions of channels and orifices were kept equal, thus, providing a similar shear stress distribution throughout the experiments. Consequently, the variables having significant impact on the shear distribution are $Q_{p}$ and the composition of the polymer solution. In this work, the variation in polymer solution includes changes in the concentration of block copolymer and additive $\mathrm{MgAc}_{2}$, which is discussed in section 2.3.

The influence of $Q_{p}$ on the integral structural dimensions of weakly segregated block copolymer solution and on the self-assembly of block copolymers is shown in Fig. 4 and Table 3. The comparison of scattering curves for a particular set of spinning parameters are shown in Figs. S2-S4, in the ESI. Firstly our data show that the ordering of micelles in all the polymer solutions is reduced as a course of the extrusion as compared to the conditions under rest, see the scattering curves in Figs. $4 a, b$ and 6 . It should be noted that the SAXS scans provide the structural information for all fiber material along the beam and for an area of ca. $28 \times 14 \mu \mathrm{m}^{2}$ in a single scan, more details are in section 1.2. Therefore, the SAXS curves mainly show the influence of extrusion on structural characteristics of the as-spun fiber, which is still a viscous polymer solution within the fiber wall up to $L_{a}$ ca. $80 \mathrm{~mm}$ depending on the polymer solution and the thickness of the as-spun fiber.

In the scattered intensity of the weakly segregated polymer solutions of $26 \mathrm{wt} \% \mathrm{PS}-b-\mathrm{P} 4 \mathrm{VP} 18^{150}$ (Fig. $4 \mathrm{a}$ ) and $25 \mathrm{wt} \%$ PS-b-P4VP $19{ }^{170}$ (Fig. 4b), no significant difference could be identified at a particular $L_{a}$ for variation of $Q_{p}$ from 0.8 to $1.2 \mathrm{~mL} / \mathrm{min}$. The main difference is a decrease of the overall intensity and a slight shift in the peak position with increasing $L_{a}$, which is attributed to the precipitation from the inner side of the fiber resulting in a change of the scattering contrast, and the evaporation of the more volatile solvent and relaxation from shear induced effects, respectively. However, with further increase in $Q_{p}$, an orientation of the structures in the polymer solution becomes evident. Depending on the shear stresses, the meso-phase structures may transform from an isotropic (Fig. 4c) to an oriented state (Fig. 4d). Figs. 4c, d are shown on a larger scale in Fig. S2 in ESI. A significant influence of the increase in $Q_{p}$ to $1.6 \mathrm{~mL} / \mathrm{min}$ can be seen on the orientation of the structures by development of a structure factor in the 2D SAXS images, at $L_{a} 10 \mathrm{~mm}$ (Figs. $4 \mathrm{~d}$ and S5). The scattering image shows an orientation effect perpendicular to the fiber axis as the ring shows the maximum intensity corresponding to the perpendicular axis of the fiber; this also applies to the structure factor. This orientation of structures is accompanied by an increase in the correlation length indicating larger domains with an increase of shear (Figs. 4a and S2 and Table 3), which shows more chain orientation of the polymers and the formation of anisotropic structures. This might influence the thermodynamic driving forces which govern the self-assembly and progression of the microphase separation which affects the membrane morphology. 
It is worth noting here that the influence of shear on the membrane morphology as observed by SEM and on the structure in as-spun fiber as observed by SAXS helps to understand the process, however, the spatial resolution of both methods is quite different. While the influence of spinning parameters in SAXS is measured for $28 \times 14 \mu \mathrm{m}^{2}$, the SEM micrographs of cross-sections near the outer surface show the morphology only for a few microns from surface. In addition, SEM investigations are done in dried membranes while in situ SAXS experiments are conducted on as-spun fibers that almost resemble the polymer solution characteristics under shear. The influence of shear during extrusion significantly varies at different $L_{a}$ due to the influence of solvent evaporation, relaxation of polymer chains and strain due to gravity.

The SEM micrographs in Figs. $4 \mathrm{e}-\mathrm{h}$ show the influence of $Q_{p}, 0.8$ and $1.6 \mathrm{~mL} / \mathrm{min}$, at $L_{a}$ of $40 \mathrm{~mm}$ on the morphology of the outer surface and the cross-section near the outer surface of the HFM. The lower extrusion rate of $0.8 \mathrm{~mL} / \mathrm{min}$ induces a lower shear rate along with a longer evaporation time. The deformation of spherical domains into ellipsoids or cylinders in the flow direction of the polymer solution can be seen in the SEM micrographs of Figs. 4e,g instead of the desired hexagonally packed pores on the outer surface. However, for $Q_{p} 1.6 \mathrm{~mL} / \mathrm{min}$, the fabrication of isoporous structure on the outer surface of HFM can be seen in Fig. $4 \mathrm{f}$ although the evaporation time is shorter due to the higher $Q_{p}$ at $L_{a} 40 \mathrm{~mm}$. The reason for a hexagonal packing of the microdomains in this comparatively short time provided in $L_{a} 40 \mathrm{~mm}$ at $Q_{p} 1.6 \mathrm{~mL} / \mathrm{min}$ might be a result of an already occurred ordering of microdomains in the block copolymer solution after experiencing higher shear rates. However, at lower shear rate these microdomains tend to align and progress in the direction of shear. At higher shear rate $\left(Q_{p} 1.6 \mathrm{~mL} / \mathrm{min}\right)$, the ordering in the weakly segregated domains tend to increase in the direction perpendicular to the fiber. Moreover, this shear induced orientation of microdomains is higher near the outer surface, which is due to the higher shear rates at the walls of the spinneret and can be seen in the SEM micrograph of the cross-section near the outer surface, see Fig. $4 \mathrm{~g}$.

The detailed influence of $Q_{p}(0.8,1.2$ and $1.6 \mathrm{~mL} / \mathrm{min})$ and $L_{a}(40$ and $100 \mathrm{~mm})$ on the morphologies of the outer surface, the inner surface, the cross-section, and cross-sections near the outer and inner surfaces of the HFM can be derived from the micrographs shown in Fig. 5. The values of $D_{p}$ and $d_{c-c}$ from the analysis of SEM micrographs of the outer surfaces are given in Table S3, which shows decrease in $D_{p}$ values with increase in $Q_{p}$. The deformation and ordering of microdomains for $Q_{p}$ of $0.8 \mathrm{~mL} / \mathrm{min}$ and $1.6 \mathrm{~mL} / \mathrm{min}$, respectively, is still in a metastable state which disappears with increase in $L_{a}$ to $100 \mathrm{~mm}$ and results in less-ordered pores on the outer surface (Fig. 5). The structures aligned on the outer surface of the HFM at $Q_{p} 0.8 \mathrm{~mL} / \mathrm{min}$ and $L_{a} 40 \mathrm{~mm}$ transform into randomly located pores oriented perpendicular to the surface at $L_{a} 100 \mathrm{~mm}$. This growth of microdomains perpendicular to the surface is driven by an increase in the evaporation time that induces a concentration gradient of volatile solvents from the top surface. ${ }^{10,60}$ The isoporous structure developed at conditions of $Q_{p} 1.6 \mathrm{~mL} / \mathrm{min}$ and $L_{a} 40$ mm also vanishes with an increase of $L_{a}$ to $100 \mathrm{~mm}$, respectively to a longer evaporation time. This disordering might have occurred due to the faster relaxation of microdomains after extrusion at high shear rate and due to the elongational forces as well. In average of $Q_{p} 0.8 \mathrm{~mL} / \mathrm{min}$ and $1.6 \mathrm{~mL} / \mathrm{min}$, the shear stress applied with $Q_{p} 1.2 \mathrm{~mL} / \mathrm{min}$ leads to isoporous 
structures for $L_{a} 40$ and $100 \mathrm{~mm}$, by offering a balance between ordering in the polymer solution due to shear stresses and disordering due to the relaxation in combination with the required evaporation time. While on the other side of the HFM, on the inner surface, with increase in $Q_{p}$ or shear stress at a particular $L_{a}$, the inner surface morphology gets slightly tightened. Also the SEM micrographs of HFM cross-sections show lesser macrovoids due to the increase in the molecular orientation and chain packing. Therefore, a variation in $Q_{p}$ strongly varies the solution characteristics during extrusion. The $Q_{p}$ together with the available evaporation time drives the block copolymer microdomains to reorganize into hexagonally packed pores on the surface. This process of self-assembly is significantly faster for more segregated or ordered block copolymer solutions because after extrusion, the block copolymer micelles try to achieve the initial equilibrium of a well-defined self-assembled nanostructure. This reorganization can be expected to occur faster in more segregated micellar solutions, what is discussed in section 2.3 for the block copolymer solutions containing $\mathrm{MgAc}_{2}$. Therefore, different block copolymer solutions cause different effects of alignment as well, as seen in our experiments. So, in contrast to the flat sheet membrane, evaporation time is not the only important variable of self-assembly and structure formation in HFM fabrication, $Q_{p}$ plays a key role as well under similar conditions.

\subsubsection{Influence of the evaporation time given by the distance $L_{a}$}

While discussing evaporation induced self-assembly, the distance between the spinneret and the precipitation bath $\left(L_{a}\right)$ remains a key factor, as it defines the evaporation time at a certain $Q_{p}$. Table 3 and Fig. 4 (particular sets are plotted in Figs. S3 and S4) show that the structural changes occur in the nm-range on the time-scale of milliseconds before the fiber is immersed in the precipitation bath. At the solution/air interface, an increase of the evaporation time increases the interfacial chain segregation which would result in an increase in peak-height of the scattering intensity. This behavior was observed during in situ SAXS study of flat sheet membranes. ${ }^{54}$ However, for the fabrication of a HF geometry, a precipitant is required on one side of the as-spun HF. The structural evaluation in this three-phase system consisting of air on one side and precipitant on the other side of a polymer solution is significantly different, and increases the complexity in understanding the macromolecular organization in $\mathrm{HF}$ fabrication. For sake of simplicity, the ratio $Q_{p} / Q_{w}$ was kept constant as two in order to provide similar conditions of coagulation from the lumen side at different volumetric flow rates $\left(Q_{p}\right)$. In addition, this gives a uniform cross-section and relatively similar membrane thickness as well.

With increasing $L_{a}$ during the HFM fabrication, the precipitation front moves inwards and increases the coagulation of polymer solution from the lumen side due to the solvent and non-solvent exchange between the flowing polymer solution and the bore fluid. The increase in coagulation increases the gelation/spinodal decomposition of the polymer solution from the lumen side. This behavior can be observed in the in situ SAXS data, which show a decrease in the peak height with increasing $L_{a}$ (Figs. $4 a, b$ and 6 ). This proofs an increase in the coagulation from the lumen side as the number of micelles decreases. Further support to this assumption is given by the observation that the peak width gets smaller indicating a narrowing of the size-distribution for micelles due to the precipitation. For a 
less viscous or weakly segregated polymer solution we also observe a lower size distribution, which hints at a higher mobility and, thus, kinetics in this situation, see Table 3. Figs. 4a,b show that the primary scattering peak vanishes completely for the commonly used weakly segregated solutions and significantly reduces for the ordered solutions (Figs. 6b,c) as well. This shows that the structure formation in as-spun fibers quenches within a short $L_{a}$. Moreover, an increase in $L_{a}$ increases the strain in the nascent fiber due to gravitational force, which changes the fiber diameters and influences the structure formation and assembly of uniform pores on the top surface of membranes (Figs. 5, 7, S7 and Tables S3, S4). Thus, for a uniform pore formation $L_{a}$ is preferred to be $\leq 100 \mathrm{~mm}$, which further significantly differs for different polymer solutions and spinning conditions.

\subsection{Influence of adding $\mathrm{MgAc}_{2}$ to the block copolymer solutions in HF spinning}
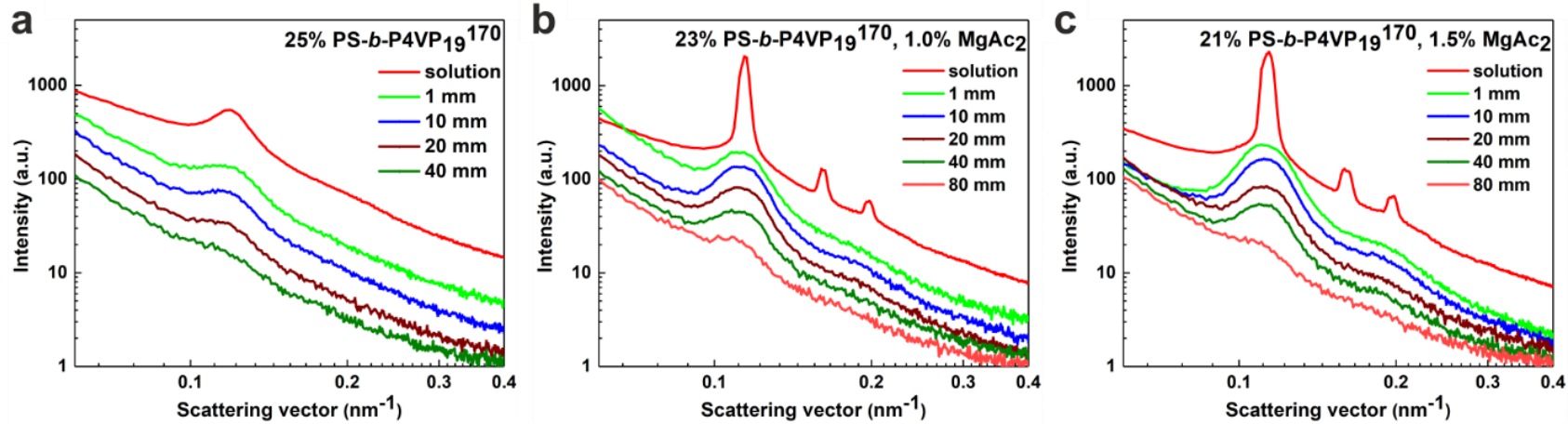

Fig. 6. SAXS of as-spun HF using block copolymer solutions having different concentrations of PS- $b-\mathrm{P} 4 \mathrm{VP} \mathrm{P}_{19}{ }^{170}$ and $\mathrm{MgAc} \mathrm{C}_{2}$ in $\mathrm{DMF} / \mathrm{THF} 50 / 50$ (wt/wt) at $Q_{p} 1.2 \mathrm{~mL} / \mathrm{min}, Q_{w} 0.6 \mathrm{~mL} / \mathrm{min}$ and different $L_{a}(\mathrm{~mm})$. (Y-offset adjusted for better presentation)

Table 4. Details of SAXS curves of as-spun fibers using different PS- $b$-P4VP ${ }_{19} 170$ block copolymer solutions at different $L_{a}$ (mm), for $Q_{p} 1.2 \mathrm{~mL} / \mathrm{min}$ and $Q_{w} 0.6 \mathrm{~mL} / \mathrm{min}$. All $q^{*}$ and $d$ have an error bar of $\pm 0.005 \mathrm{~nm}^{-1}$ and $\pm 1.1 \mathrm{~nm}$, respectively.

\begin{tabular}{|c|c|c|c|c|c|c|c|}
\hline \multirow{2}{*}{$\begin{array}{c}L_{a} \\
(\mathrm{~mm})\end{array}$} & \multicolumn{2}{|c|}{$25 w t \%$} & \multicolumn{2}{|c|}{$23 \mathrm{wt} \%$ and $1.0 \mathrm{wt} \% \mathrm{MgAc}_{2}$} & \multicolumn{3}{|c|}{$21 \mathrm{wt} \%$ and $1.5 \mathrm{wt} \% \mathrm{MgAc}_{2}$} \\
\hline & $q^{*}\left(\mathrm{~nm}^{-1}\right)$ & $d(\mathrm{~nm})$ & $q^{*}\left(\mathrm{~nm}^{-1}\right)$ & $d(\mathrm{~nm})$ & $q^{*}\left(\mathrm{~nm}^{-1}\right)$ & $q^{2 n d}\left(\mathrm{~nm}^{-1}\right)$ & $d(\mathrm{~nm})^{1}$ \\
\hline Solution & 0.120 & 52.4 & 0.114 & 55.1 & 0.114 & 0.161 & 55.1 \\
\hline 1 & 0.120 & 52.4 & 0.109 & 57.6 & 0.109 & 0.205 & 57.6 \\
\hline 10 & 0.119 & 52.8 & 0.111 & 56.6 & 0.111 & 0.193 & 56.6 \\
\hline 20 & 0.116 & 54.2 & 0.111 & 56.6 & 0.110 & 0.194 & 57.1 \\
\hline 40 & 0.113 & 55.6 & 0.108 & 58.2 & 0.107 & 0.200 & 58.7 \\
\hline 80 & - & - & 0.105 & 59.8 & - & - & - \\
\hline
\end{tabular}




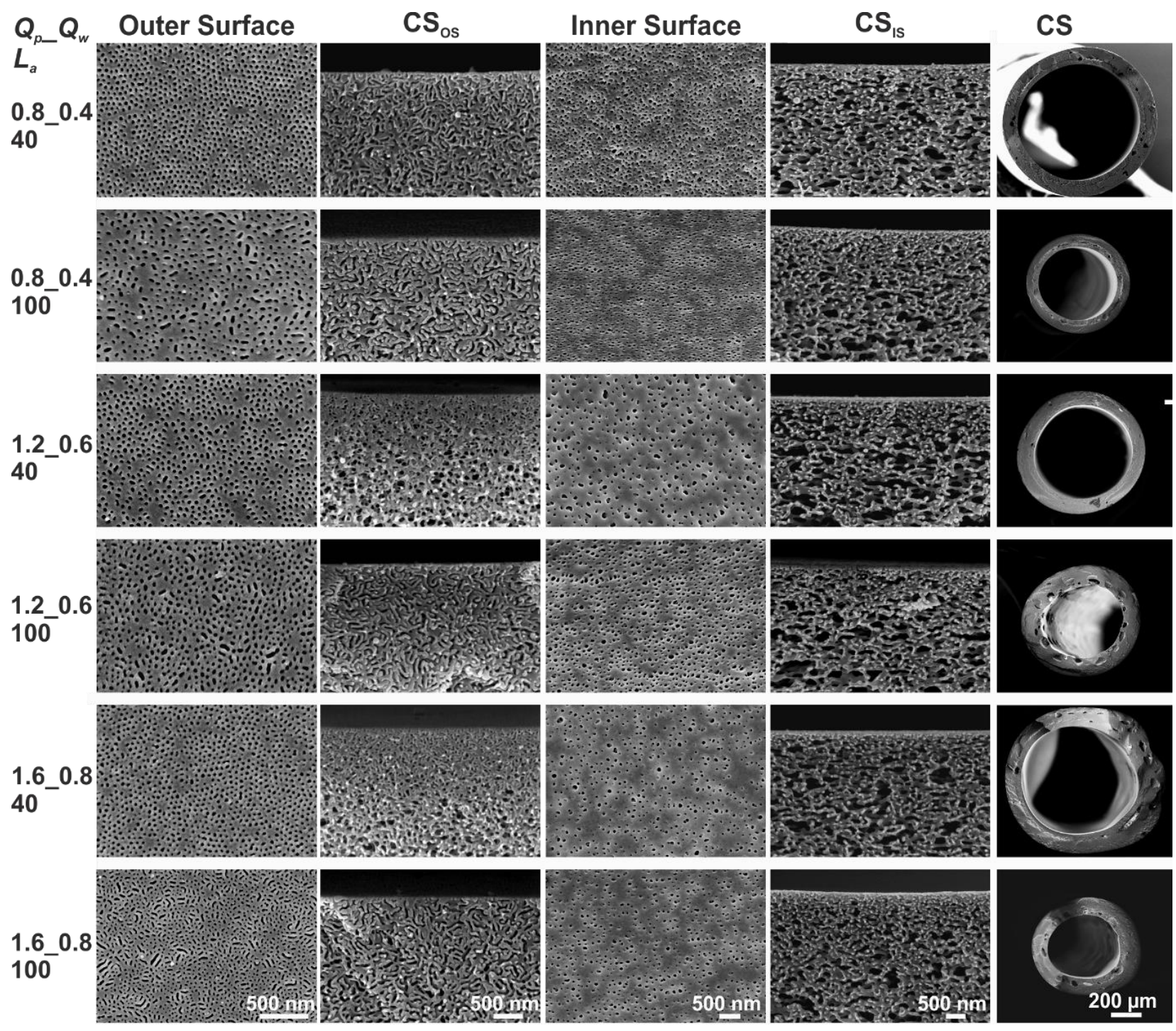

Fig. 7. The SEM micrographs show the influence of spinning parameters $\left(Q_{p_{-}} Q_{w_{-}} L_{a}\right)$ on the morphology of the outer surface, cross-sections near the outer surface $\left(\mathrm{CS}_{\mathrm{os}}\right)$, the inner surface, cross-sections near the inner surfaces $\left(\mathrm{CS}_{\text {is }}\right)$ and the full crosssection (CS) of HFM. The HFM were spun using block copolymer solution of $21 \mathrm{wt} \% \mathrm{PS}-b$-P4VP $19^{170}$ and $1.5 \mathrm{wt} \% \mathrm{MgAc} 2$ in DMF/THF $50 / 50$ (wt/wt) for $Q_{p} 0.8,1.2$ and $1.6 \mathrm{~mL} / \mathrm{min}$, at $L=L_{a}, 40$ and $100 \mathrm{~mm}$. The SEM micrographs in a column have the same scale bar.

The SAXS curves in Fig. 6 show the influence of the extrusion parameters on the ordering of different block copolymer solutions having different amount of $\mathrm{MgAc}_{2}$, at a certain $L_{a}$. The comparison of solutions for a particular set of spinning parameters is shown in Fig. S6, in ESI. During extrusion, the shear stresses distort the structural features of the polymer solution, i.e., bcc in polymer solutions having $21 \mathrm{wt} \% \mathrm{PS}-b-\mathrm{P}_{4} \mathrm{VP}_{19}{ }^{170}$ and $_{1.5} \mathrm{wt}^{2} \mathrm{MgAc}_{2}$, and 23 wt\% PS- $b-\mathrm{P}_{\mathrm{VVP}}{ }_{19}{ }^{170}$ and $1.0 \mathrm{wt} \% \mathrm{MgAc}_{2}$ in DMF/THF 50/50 (wt/wt). After extrusion, the sharpness and intensity of the primary peak decreases and the peak position shifts to a slightly lower $q$ as compared to the respective solution. The scattering pattern of the as-spun fiber, at $L_{a} 1 \mathrm{~mm}$, from spinning of $25 \mathrm{wt} \% \mathrm{PS}-b$-P4VP $19{ }^{170}$ 
solution does not show a significant change in the peak position as compared to the steady solution while the peak gets wider and loses the intensity, as discussed in section 2.1 (Figs. 4b or 6a). However, in case of the ordered solutions, the higher order peaks disappear and with increasing $L_{a}$ even the shoulder becomes gradually harder to discern (Figs. 6b,c). This confirms that the extrusion of an ordered solution results in a lesser or only partially ordered solution afterwards.

Interestingly, just after extrusion at $L_{a}$ of $1 \mathrm{~mm}$, the scattering curve from polymer solution $23 \mathrm{wt} \% \mathrm{PS}-b-\mathrm{P}_{\mathrm{VVP}}{ }_{19}{ }^{170}$ and $1.0 \mathrm{wt} \% \mathrm{MgAc}_{2}$ in DMF/THF 50/50 (wt/wt) shows only one broad peak with an increase in domain spacing as compared to the respective solution, see Fig. $6 \mathrm{~b}$ and Table 4. However, the second shoulder in the scattering curves appears at $L_{a}$ of 10 and $20 \mathrm{~mm}$ with a decrease in domain spacing, which again disappears for $L_{a} \mathrm{ca} .40 \mathrm{~mm}$ and shows an increase in domain spacing. This trend in SAXS curves and domain spacing values hint at ongoing structural transitions in the block copolymer solution. We speculate that the competing interactions of shear stresses during extrusion, relaxation after extrusion, and the increase in segregation of block copolymers due to evaporation are responsible for this behaviour. During extrusion, the structural ordering of the block copolymers is disturbed and due to the shear stresses the ordered micelles might enlarge showing an increase in domain spacing. After extrusion, these structures in as-spun polymer solution try to achieve the initial equilibrium of block copolymer solution by releasing the shear effects and shows a decrease in domain spacing. On the other hand, with increasing $L_{a}$ the influence of evaporation on the self-assembly and the precipitation from the lumen side on coagulation increases significantly. Thus, the observation of the second shoulder for block copolymer solutions of $23 \mathrm{wt} \%$ with $1.0 \mathrm{wt} \%$ $\mathrm{MgAc}_{2}$ shows that up to $20 \mathrm{~mm}$ the bulk relaxation dominates which is overwhelmed by the segregation and selfassembly afterwards.

A similar trend in the height of the second shoulder and in the domain spacing can also be seen during the spinning of the solution containing $21 \mathrm{wt} \% \mathrm{PS}-b-\mathrm{P}_{\mathrm{VPP}}{ }_{19}{ }^{170}$ and $1.5 \mathrm{wt} \% \mathrm{MgAc}_{2}$ in DMF/THF 50/50 (wt/wt), Fig. 6c and Table 4. However, here the second shoulder is stronger and can be seen up to $L_{a} c$. $40 \mathrm{~mm}$. This indicates that with increasing the concentration of $\mathrm{MgAc}_{2}$ from $1.0 \mathrm{wt} \%$ to $1.5 \mathrm{wt} \%$ and respectively decreasing the P4VP segments (with decrease in block copolymer concentration) the cation-pyridine complexation gets stronger and the structural ordering gets kinetically trapped. So, due to the higher $\mathrm{MgAc}_{2}$ concentration, the initial structural properties of block copolymer solutions are more dominating and the system tries to return to the initial state faster as compared to the pristine solution after coming out of the spinneret. This is induced by the increased effective $\chi$ parameter. As discussed in section 2.1, the solution scattering curves in Fig. 2 show that the increased addition of $M g A c_{2}$ leads to more prominent microphase separation in the solution of polymeric amphiphiles, which might be due to less mobility of polymer chains or reduced micelle mobility, and all together lowers the structural transitions.

The SEM micrographs in Fig. 7 show the influence of spinning parameters, $Q_{p}$ of $0.8,1.2$ and $1.6 \mathrm{~mL} / \mathrm{min}$, and $L_{a}$ of 40 and $100 \mathrm{~mm}$, on the morphology of HFM spun using an ordered block copolymer solution of $21 \mathrm{wt} \%$ PS- $b$ $\mathrm{P} 4 V P_{19}{ }^{170}$ and $1.5 \mathrm{wt} \% \mathrm{MgAc}_{2}$ in DMF/THF 50/50 (wt/wt). The influence of solution characteristics on the formation of isoporous structures can be seen in the SEM micrographs of the outer surface of the HFM spun using two different 
solutions, in Figs. 5 and 7. The HFM with isoporous outer surface could be achieved for a wider range of $Q_{p}(0.8,1.2$ and $1.6 \mathrm{~mL} / \mathrm{min}$ ) at $L_{a} 40 \mathrm{~mm}$ using ordered solution containing $\mathrm{MgAc}_{2}$ (Fig. 7) as compared to the pristine weakly segregated solution having higher polymer concentration of $25 \mathrm{wt} \% \mathrm{PS}-b-\mathrm{P} 4 \mathrm{VP}_{19}{ }^{170}$ in DMF/THF 50/50 (wt/wt) (Figs. 5 and S7). For $Q_{p} 0.8 \mathrm{~mL} / \mathrm{min}$, at $L_{a} 40 \mathrm{~mm}$, formation of isoporous structures can be observed for the ordered solution containing $\mathrm{MgAc}_{2}$, while the pristine weakly segregated solution shows a random alignment of cylinders on the outer surface. This shows that the shear induced ordering for isoporous structure formation is more probable even at lower shear rates for already ordered solutions, after losing the crystallinity during extrusion, while for the weakly segregated solutions higher shear rate is necessary to achieve ordering of the microdomains.

The metastable hexagonal ordering of microdomains on the outer surface disappears for all three $Q_{p}$ values $(0.8,1.2$ and $1.6 \mathrm{~mL} / \mathrm{min}$ ) within $L_{a}$ of $100 \mathrm{~mm}$. The SEM micrographs of cross-sections near the outer surface show the random cylindrical growth of micelles in this short evaporation time, see Fig. 7. However, for the weakly segregated solution, in Fig. 5, such random cylindrical ordering in the cross-section near the outer surface is missing and a rather asymmetric structure can be recognized, and the self-assembled isoporous structures can be seen for $Q_{p}$ of 1.2 $\mathrm{mL} / \mathrm{min}$, up to $L_{a}$ of $100 \mathrm{~mm}$ (Fig. 5). An influence of solution characteristics can also be observed on the morphology of the inner surface of HFM, where the pores look more elongated in Fig. 5 as compared to Fig. 7. Also, the morphology of cross-sections near the inner surface is significantly different. Therefore, the HFM morphology completely depends on the solution characteristics and the spinning parameters. The isoporous structure formation and growth of microdomains is faster and facilitated in ordered solutions containing $\mathrm{MgAc}_{2}$ as compared to the pristine solutions.

\section{Conclusion}

We present the first in situ SAXS measurements of the self-organization of block copolymers during HF spinning and its relation with the solution characteristics and the spinning parameters. For this, we selected the ordered solution having $\mathrm{MgAc}_{2}$ with comparatively lower polymer concentrations and the weakly segregated pristine PS- $b$-P4VP block copolymer solutions. The real-time synchrotron SAXS measurements provide insight into the microscopic processes relevant for ordering of microdomains and their self-assembly after extrusion of concentrated block copolymer solutions. These structural features are correlated to the structure in the block copolymer solutions under rest and to the final morphology of the flat sheet and HF membranes, investigated by ex situ SEM. The SAXS data show that the shear stresses during the spinning of block copolymer solution results in disordering of already ordered solution and reduces the micellization in weakly segregated solution as well. We note that the dependence of structure formation on the block copolymer solution and the polymer flow rate results from a subtle balance between the driving force of the relaxation of macromolecules after extrusion and the evaporation induced self-assembly. The extrusion rate governs the mechanism of self-assembly along with evaporation time, which is strongly influenced by 
the segregation conditions within the block copolymer solution. The rather fast ordering of microdomains as hexagonally packed pores on the outer surface could be observed for higher extrusion rates of block copolymer solutions which is further facilitated in more segregated block copolymer solutions, i.e., MgAc $\mathrm{C}_{2}$ containing ordered solutions. The morphological investigations by SEM show that the $\mathrm{MgAc}_{2}$ containing ordered solution shows faster evaporation induced self-assembly on the outer surface of HFM after loosing the ordering during extrusion. The ordered solution provide isoporous structures for wider range of polymer flow rate and in shorter air gap distance as compared to the weakly segregated pristine solution.

\section{Conflicts of interest}

There are no conflicts to declare.

\section{Acknowledgements}

The authors gratefully acknowledge Brigitte Lademann for synthesis of the block copolymers, Silvio Neumann for NMR, Maren Brinkmann for GPC measurements, and Anke-Lisa Metze for TEM investigations and support in analysis of the SEM micrographs. We acknowledge Hilmar Burmester, Jens Brehling and Dirk Jan Siemers for supporting in the adaptation of the spinning set-up. The SAXS experiments were carried out at the P03 beamline of light source PETRA III at DESY, a member of the Helmholtz Association (HGF). We thank Dr. Matthias Schwarzkopf for help with setting up the beamline P03 at DESY.

\section{Notes and references}

\section{References:}

1. L. Leibler, Macromolecules, 1980, 13, 1602-1617.

2. $\quad$ F. S. Bates and G. H. Fredrickson, Phys. Today, 1999, 52, 32-38.

3. V. Abetz and A. Boschetti-de-Fierro, in Polymer Science: A Comprehensive Reference, (Eds: K. Matyjaszewski and M. Möller), Elsevier, Amsterdam, 2012, DOI: 10.1016/B9780-444-53349-4.00192-8, 3-44.

4. F. S. Bates, M. A. Hillmyer, T. P. Lodge, C. M. Bates, K. T. Delaney and G. H. Fredrickson, Science, 2012, 336, 434-440.

5. I. Hamley, The Physics of Block Copolymers, Oxford University Press, 1998.

6. M. S. Silverstein, N. R. Cameron and M. A. Hillmyer, Porous Polymers, John Wiley \& Sons, Inc., 2011.

7. S. Förster and T. Plantenberg, Angew. Chem. Int.Ed., 2002, 41, 688-714.

8. Q. Yang and K. Loos, Polym. Chem., 2017, 8, 641-654.

9. V. Abetz, K. Kremer, M. Müller and G. Reiter, Macromol. Chem. Phys., 1800334. DOI: 10.1002/macp.201800334

10. V. Abetz, Macromol. Rapid Commun., 2015, 36, 10-22.

11. C. M. Bates and F. S. Bates, Macromolecules, 2017, 50, 3-22. 
12. J. I. Clodt, B. Bajer, K. Buhr, J. Hahn, V. Filiz and V. Abetz, J. Membr. Sci., 2015, 495, 334-340.

13. W. A. Phillip, R. Mika Dorin, J. Werner, E. M. V. Hoek, U. Wiesner and M. Elimelech, Nano Lett., 2011, 11, 2892-2900.

14. Y. Zhang, N. E. Almodovar-Arbelo, J. L. Weidman, D. S. Corti, B. W. Boudouris and W. A. Phillip, npj Clean Water, 2018, 1, 2.

15. I. Sadeghi, P. Kaner and A. Asatekin, Chem. Mater., 2018, 30, 7328-7354.

16. K.-V. Peinemann, V. Abetz and P. F. W. Simon, Nat. Mater., 2007, 6, 992-996.

17. S. Rangou, K. Buhr, V. Filiz, J. I. Clodt, B. Lademann, J. Hahn, A. Jung and V. Abetz, J. Membr. Sci., 2014, 451, 266-275.

18. M. Radjabian, C. Abetz, B. Fischer, A. Meyer and V. Abetz, ACS Appl. Mater. Interfaces, 2017, 9, 31224-31234.

19. J. I. Clodt, S. Rangou, A. Schröder, K. Buhr, J. Hahn, A. Jung, V. Filiz and V. Abetz, Macromol. Rapid Commun., 2013, 34, 190-194.

20. M. Gallei, S. Rangou, V. Filiz, K. Buhr, S. Bolmer, C. Abetz and V. Abetz, Macromol. Chem. Phys., 2013, 214, 1037-1046.

21. S. P. Nunes, A. R. Behzad, B. Hooghan, R. Sougrat, M. Karunakaran, N. Pradeep, U. Vainio and K.-V. Peinemann, ACS Nano, 2011, 5, 3516-3522.

22. C. Liedel, C. W. Pester, M. Ruppel, V. S. Urban and A. Böker, Macromol. Chem. Phys., 2012, 213, 259-269.

23. M. Radjabian, J. Koll, K. Buhr, U. A. Handge and V. Abetz, Polymer, 2013, 54, 18031812.

24. M. Radjabian, J. Koll, K. Buhr, U. Vainio, C. Abetz, U. A. Handge and V. Abetz, Polymer, 2014, 55, 2986-2997.

25. K. Sankhala, J. Koll, M. Radjabian, U. A. Handge and V. Abetz, Adv. Mater. Interfaces, 2017, 4, 1600991.

26. R. Hilke, N. Pradeep, P. Madhavan, U. Vainio, A. R. Behzad, R. Sougrat, S. P. Nunes and K.-V. Peinemann, ACS Appl. Mater. Interfaces, 2013, 5, 7001-7006.

27. N. Noor, J. Koll, M. Radjabian, C. Abetz and V. Abetz, Macromol. Rapid Commun., 2016, 37, 414-419.

28. Y. Liu, T. Liu, Y. Su, H. Yuan, T. Hayakawa and X. Wang, J. Membr. Sci., 2016, 506, 110.

29. K. Sankhala, J. Koll and V. Abetz, ACS Macro Letters, 2018, 7, 840-845.

30. W. J. Koros and C. Zhang, Nat. Mater., 2017, 16, 289.

31. R. Baker, Membrane Technology and Applications, 2nd Edition, John Wiley \& Sons, Ltd., 2004.

32. H. Strathmann, Introduction to Membrane Science and Technology, Wiley-VCH, 2011.

33. T.-S. N. Chung, in Advanced Membrane Technology and Applications (Eds: N. N. Li, A. G. Fane, W. S. Ho and T. Matsuura), John Wiley \& Sons, Inc., 2008, DOI: 10.1002/9780470276280.ch31, 821-839.

34. N. Peng, N. Widjojo, P. Sukitpaneenit, M. M. Teoh, G. G. Lipscomb, T.-S. Chung and J.Y. Lai, Prog. Polym. Sci., 2012, 37, 1401-1424.

35. W.-L. Hung, D.-M. Wang, J.-Y. Lai and S.-C. Chou, J. Membr. Sci., 2016, 505, 70-81.

36. G. R. Guillen, Y. Pan, M. Li and E. M. V. Hoek, Ind. Eng. Chem. Res., 2011, 50, 37983817. 
37. P. K. Pranzas, A. Knöchel, K. Kneifel, H. Kamusewitz, T. Weigel, R. Gehrke, S. S. Funari and R. Willumeit, Anal. Bioanal. Chem., 2003, 376, 602-607.

38. S. Dami, C. Abetz, B. Fischer, M. Radjabian, P. Georgopanos and V. Abetz, Polymer, 2017, 126, 376-385.

39. L. Oss-Ronen, J. Schmidt, V. Abetz, A. Radulescu, Y. Cohen and Y. Talmon, Macromolecules, 2012, 45, 9631-9642.

40. M. Radjabian, C. Abetz, B. Fischer, A. Meyer, B. Lademann and V. Abetz, Macromol. Chem. Phys., 2017, 218, 1600587.

41. R. M. Dorin, D. S. Marques, H. Sai, U. Vainio, W. A. Phillip, K.-V. Peinemann, S. P. Nunes and U. Wiesner, ACS Macro Lett., 2012, 1, 614-617.

42. D. S. Marques, U. Vainio, N. M. Chaparro, V. M. Calo, A. R. Bezahd, J. W. Pitera, K.-V. Peinemann and S. P. Nunes, Soft Matter, 2013, 9, 5557-5564.

43. S. P. Nunes, M. Karunakaran, N. Pradeep, A. R. Behzad, B. Hooghan, R. Sougrat, H.-Z. He and K.-V. Peinemann, Langmuir, 2011, 27, 10184-10190.

44. R. M. Dorin, D. S. Marques, H. Sai, U. Vainio, W. A. Phillip, K.-V. Peinemann, S. P. Nunes and U. Wiesner, ACS Macro Lett., 2012, 1, 614-617.

45. W. Bras and A. J. Ryan, Adv. Colloid Interface Sci., 1998, 75, 1-43.

46. M. Cakmak, A. Teitge, H. G. Zachmann and J. L. White, J. Polym. Sci., Part B: Polym. Phys., 1993, 31, 371-381.

47. C. Martin, G. Eeckhaut, A. Mahendrasingam, D. J. Blundell, W. Fuller, R. J. Oldman, S. J. Bingham, T. Dieing and C. Riekel, J. Synchrotron Radiat., 2000, 7, 245-250.

48. W. Bras, Nucl. Instrum. Methods Phys. Res., Sect. B, 2003, 199, 90-97.

49. C. Riekel, Nucl. Instrum. Methods Phys. Res. Sect. B, 2003, 199, 106-111.

50. E. L. Heeley, T. Gough, D. J. Hughes, W. Bras, J. Rieger and A. J. Ryan, Polymer, 2013, 54, 6580-6588.

51. W. Bras, S. Koizumi and N. J. Terrill, IUCrJ, 2014, 1, 478-491.

52. D. S. Marques, R. M. Dorin, U. Wiesner, D.-M. Smilgies, A. R. Behzad, U. Vainio, K.-V. Peinemann and S. P. Nunes, Polymer, 2014, 55, 1327-1332.

53. X. Gu, I. Gunkel, A. Hexemer, W. Gu and T. P. Russell, Adv. Mater., 2014, 26, 273-281.

54. C. Stegelmeier, A. Exner, S. Hauschild, V. Filiz, J. Perlich, S. V. Roth, V. Abetz and S. Förster, Macromolecules, 2015, 48, 1524-1530.

55. Y. Gu, R. M. Dorin, K. W. Tan, D.-M. Smilgies and U. Wiesner, Macromolecules, 2016, 49, 4195-4201.

56. A. Buffet, A. Rothkirch, R. Doehrmann, V. Koerstgens, M. M. Abul Kashem, J. Perlich, G. Herzog, M. Schwartzkopf, R. Gehrke, P. Müller-Buschbaum and S. V. Roth, J. Synchrotron Radiat, 2012, 19, 647-653.

57. M. Basham, J. Filik, M. T. Wharmby, P. C. Y. Chang, B. El Kassaby, M. Gerring, J. Aishima, K. Levik, B. C. A. Pulford, I. Sikharulidze, D. Sneddon, M. Webber, S. S. Dhesi, F. Maccherozzi, O. Svensson, S. Brockhauser, G. Náray and A. W. Ashton, J. Synchrotron Radiat., 2015, 22, 853-858.

58. Q. Zhang, Y. Gu, Y. M. Li, P. A. Beaucage, T. Kao and U. Wiesner, Chem. Mater., 2016, 28, 3870-3876.

59. H. Ogawa, M. Takenaka, T. Miyazaki, A. Fujiwara, B. Lee, K. Shimokita, E. Nishibori and M. Takata, Macromolecules, 2016, 49, 3471-3477.

60. W. A. Phillip, M. A. Hillmyer and E. L. Cussler, Macromolecules, 2010, 43, 7763-7770. 